\title{
An association between parvovirus B19 infection and the severity of coronary atherosclerosis
}

\author{
Elżbieta Paszek ${ }^{1 \star}$, Aleksander Wilk $^{2 *}$, Jakub Palacz ${ }^{3}$, Artur Majer $^{4}$, Bogusław Kapelak $^{5}$, Roman Pfitzner ${ }^{5}$ \\ 1 Department of Interventional Cardiology, Institute of Cardiology, John Paul II Hospital, Kraków, Poland \\ 2 Department of Neurosurgery and Neurotraumatology, University Hospital, Kraków, Poland \\ 3 Department of General and Vascular Surgery, University Hospital, Opole, Poland \\ 4 Department of Trauma and Orthopedics, Gawlik Regional Hospital, Sucha Beskidzka, Poland \\ 5 Department of Cardiovascular Surgery and Transplantology, Institute of Cardiology, Jagiellonian University Medical College, Kraków, Poland
}

\section{Correspondence to:} Elżbieta Paszek, MD, PhD Department of Interventional Cardiology, Institute of Cardiology, John Paul II Hospital, ul. Prądnicka 80, 31-202, Kraków Poland, phone: +48126143501 , email: elzbieta.m.paszek@gmail.com Received: June 11, 2019. Revision accepted: July 4, 2019. Published online: July 9, 2019. Kardiol Pol. 2019; 77 (9): 875-877 doi:10.33963/KP.14893 Copyright by the Author(s), 2019

* EP and AW contributed equally to this work.
Introduction Besides the well-established risk factors for the development of coronary atherosclerosis, such as sex, hypertension, dyslipidemia, diabetes, and smoking, there have been studies showing a correlation between infections and coronary artery disease (CAD). There is a substantial amount of data suggesting a possible involvement of Chlamydophila pneumoniae, ${ }^{1}$ herpes simplex virus $2,{ }^{2}$ cytomegalovirus, ${ }^{3}$ Helicobacter pylori, ${ }^{4}$ or Porphyromonas gingivalis ${ }^{5}$ in the development or exacerbation of atherosclerosis. It is postulated that they might exert an atherogenic effect by causing systemic proinflammatory conditions. Nevertheless, none of the above pathogens targets the human endothelium. ${ }^{1}$ One pathogen with direct tropism for human endothelial cells is parvovirus B19, which has been shown not only to infect endothelial cells but also to impair their regeneration. ${ }^{6}$ Since atherosclerosis is strongly dependent on endothelial dysfunction, this suggests that parvovirus B19 could be involved in plaque development. Parvovirus B19 infections are common. An epidemiologic study indicated that a parvovirus B19 infection has affected $80 \%$ of the Polish population at the age of 40 years. ${ }^{7}$ Clinical presentations of the infection range from erythema infectiosum in children to arthropathy or myocarditis in adults, with a suggested involvement in the pathogenesis of rheumatic diseases. However, a parvovirus B19 infection may often be asymptomatic or show influenza-like symptoms only. ${ }^{8}$

The aim of this study was to determine whether there is an association between anti-parvovirus B19 immunoglobulin G ( $\operatorname{Ig} G)$ antibodies and the severity of CAD.
Methods This was an observational study conducted in 2012 at the Department of Cardiovascular Surgery and Transplantology, Institute of Cardiology, Jagiellonian University Medical College (Kraków, Poland). We included 76 consecutive patients referred for coronary artery bypass grafting (CABG) due to stable CAD. The only exclusion criterion was a referral for an urgent procedure. All patients provided written informed consent to participate in the study, and the study was approved by the Jagiellonian University Ethics Committee.

Patients were screened for typical risk factors of atherosclerosis and history of myocardial infarction. Coronary angiograms were analyzed and the Gensini score was used for a quantitative analysis of coronary atherosclerosis. ${ }^{9}$

Parvovirus B19 diagnostics Venous blood was collected before CABG, centrifuged, and the supernatants were stored at a temperature of $-80^{\circ} \mathrm{C}$. The level of anti-parvovirus B19 IgG antibodies was measured using an enzyme-linked immunosorbent assay (recomWell Parvovirus B19 IgG kit; Mikrogen Diagnostik, Neuried, Germany). Based on the results, patients were divided into a group positive for anti-parvovirus B19 IgG antibodies (patients who have suffered the infection) and a group negative for anti-parvovirus B19 IgG antibodies (patients with no evidence of the infection).

Statistical analysis Normal distribution of continuous variables was assessed using the Shapiro-Wilk test. For the association of 
nominal variables, the Pearson $\mathrm{X}^{2}$ test was used. The Mann-Whitney test was used in the case of one nominal and one continuous variable (no continuous variables showed a normal distribution in any of the groups). A $P$ value of less than 0.05 was considered significant.

Results and discussion Of the 76 patients, 63 tested positive for the presence of parvovirus B19 IgG antibodies (82.9\%), which is consistent with epidemiologic data. ${ }^{7}$ The distribution of risk factors for CAD was typical and did not differ between seropositive and seronegative patients. We found that seropositive patients were more likely to have a history of myocardial infarction (36.5\% vs $7.7 \%, P=0.049$ ). We also observed a larger atherosclerotic burden in the seropositive than in the seronegative group (Gensini score, 98 vs $70, P=0.049$ ). Detailed results are presented in TABLE 1 .

Based on the assessed indicators of CAD severity, it seems plausible that a parvovirus B19 infection may influence the development of coronary atherosclerosis. Since one of the first stages and hallmarks of atherosclerosis is endothelial dysfunction, it is possible that infectious agents targeting the endothelium and causing inflammation, such as parvovirus B19, might contribute to the development of atherosclerotic plaques. This hypothesis is in fact supported by published data. ${ }^{10}$ Liu et a $1^{11}$ performed a serology analysis of 565 individuals with CAD and healthy controls and demonstrated that patients with CAD were significantly more often positive for anti-parvovirus B19 IgG antibodies than controls. An interesting study by Niccoli et $\mathrm{al}^{12}$ showed that the presence of parvovirus B19 DNA on a balloon used to predilate coronary lesions was a predictor of major adverse cardiovascular events defined as a composite of cardiac death, myocardial infarction, and clinically driven target lesion revascularization.

Parvovirus B19 genetic material can be found in cells in a quiescent state, at levels that do not exert an immune response. ${ }^{13}$ It has been demonstrated that a simultaneous infection with parvovirus B19 and adenoviruses can augment the expression of parvovirus B19 proteins within endothelial cells. ${ }^{14}$ Therefore, it is possible that an isolated parvovirus B19 infection of the endothelium does not have the potency to lead to a clinically relevant effect on atherosclerosis and requires a coinfection with other viruses.

Parvovirus B19 material can be found in around $1 \%$ of patients with myocarditis. ${ }^{15}$ Still, none of the patients in our group had a history of myocarditis. This might be due to the fact that most parvovirus B19 infections are asymptomatic or display influenza-like symptoms and may have been missed. Since the median age of patients was above 60 years and myocarditis usually affects individuals aged 20 to 40 years old, it is possible that some myocardial infections had occurred in the parvovirus B19-positive group in the distant past and were not diagnosed at the time of presentation.

In conclusion, our results show that patients positive for anti-parvovirus B19 antibodies had a larger atherosclerotic burden measured by the Gensini score and were more likely to have suffered from a myocardial infarction than seronegative patients. However, this was a preliminary study on a small group of patients. Therefore, conclusions must be interpreted with caution and should be confirmed in a larger population. Still, as arterial endothelial cell dysfunction underlies the development of atherosclerosis, it seems that the association between parvovirus B19 infection and $\mathrm{CAD}$ is an interesting research field.

TABLE 1 Characteristics of patients with seropositivity and seronegativity for anti-parvovirus B19 immunoglobulin G antibodies

\begin{tabular}{llll} 
Parameter & Seropositive patients $(\mathrm{n}=63)$ & Seronegative patients $(\mathrm{n}=13)$ & $\mathbf{P}$ value \\
Age, $y$, median (min-max; IQR) & $63(47-80 ; 14)$ & $62(51-82 ; 18)$ & $0.65^{\mathrm{a}}$ \\
\hline Sex, male, $\mathrm{n}(\%)$ & $51(81.0)$ & $10(77.0)$ & $0.40^{\mathrm{b}}$ \\
\hline Hypertension, $\mathrm{n}(\%)$ & $50(79.4)$ & $13(100.0)$ & $0.40^{\mathrm{b}}$ \\
\hline Dyslipidemia, $\mathrm{n}(\%)$ & $44(69.8)$ & $11(84.6)$ & $0.57^{\mathrm{b}}$ \\
\hline Diabetes, $\mathrm{n}(\%)$ & $22(34.9)$ & $4(30.8)$ & $0.12^{\mathrm{b}}$ \\
\hline Active smoking, $\mathrm{( \% )}$ & $38(60.3)$ & $8(61.5)$ & $0.84^{\mathrm{b}}$ \\
\hline Preprocedural LVEF, median (min-max; IQR) & $52(35-70 ; 6)$ & $52(40-70 ; 6)$ & $0.91^{\mathrm{a}}$ \\
\hline History of MI, $\mathrm{n}(\%)$ & $23(36.5)$ & $1(7.7)$ & $0.049^{\mathrm{b}}$ \\
\hline Gensini score, median (min-max; IQR) & $98(46.5-152.5 ; 33.5)$ & $70(45-134 ; 38)$ & $0.049^{\mathrm{a}}$ \\
\hline
\end{tabular}

a Mann-Whitney test; b $\chi^{2}$ test

Abbreviations: IgG, immunoglobulin G; IQR, interquartile range; max, maximum; MI, myocardial infarction; min, minimum; LVEF, left ventricular ejection fraction 


\section{ARTICLE INFORMATION}

ACKNOWLEDGMENTS The study was funded from an institutional grant (to AW, EP, and JP).

CONFLICT OF INTEREST None declared.

OPEN ACCESS This is an Open Access article distributed under the terms of the Creative Commons Attribution-NonCommercial-NoDerivatives 4.0 International License (CC BY-NC-ND 4.0), allowing third parties to download articles and share them with others, provided the original work is properly cited, not changed in any way, distributed under the same license, and used for noncommercial purposes only. For commercial use, please contact the journal office at kardiologiapolska@ptkardio.pl.

HOW TO CITE Paszek E, Wilk A, Palacz J, et al. An association between parvovirus B19 infection and the severity of coronary atherosclerosis. Kardiol Pol. 2019; 77: 875-877. doi:10.33963/KP.14893

\section{REFERENCES}

1 Joshi R, Khandelwal B, Joshi D, et al. Chlamydophila pneumoniae infection and cardiovascular disease. N Am J Med Sci. 2013; 5: 169-181.

2 Mendy A, Vieira ER, Gasana J. Seropositivity to herpes simplex virus type 2, but not type 1 is associated with premature cardiovascular diseases: a population-based cross-sectional study. Atherosclerosis. 2013; 231: 18-21.

3 Shmeleva EV, Boag SE, Murali S, et al. Differences in immune responses between CMV-seronegative and -seropositive patients with myocardial ischemia and reperfusion. Immun Inflamm Dis. 2015; 3: 56-70.

4 Mayr M, Kiechl S, Mendall MA, et al. Increased risk of atherosclerosis is confined to CagA-positive Helicobacter pylori strains: prospective results from the Bruneck study. Stroke. 2003; 34: 610-615

5 Hayashi C, Viereck J, Hua N, et al. Porphyromonas gingivalis accelerates inflammatory atherosclerosis in the innominate artery of ApoE deficient mice. Atherosclerosis. 2011; 215: 52-59.

6 Schmidt-Lucke C, Zobel T, Schrepfer S, et al. Impaired endothelial regeneration through human parvovirus B19-infected circulating angiogenic cells in patients with cardiomyopathy. J Infect Dis. 2015; 212: 1070-1081.

7 Siennicka J, Stefanoff P, Trzcińska A, et al. Seroprevalence study of parvovirus B19 in Poland [in Polish]. Przegl Epidemiol. 2006; 60: 571-580.

8 Servey JT, Reamy BV, Hodge J. Clinical presentations of parvovirus B19 infection. Am Fam Physician. 2007; 75: 373-376.

9 Gensini GG. A more meaningful scoring system for determining the severity of coronary heart disease. Am J Cardiol. 1983; 51: 606.

10 Vallbracht KB, Schwimmbeck PL, Kühl U, et al. Differential aspects of endothelial function of the coronary microcirculation considering myocardial virus persistence, endothelial activation, and myocardial leukocyte infiltrates. Circulation. 2005; 111: 1784-1791.

11 Liu SC, Tsai CT, Wu CK, et al. Human parvovirus b19 infection in patients with coronary atherosclerosis. Arch Med Res. 2009; 40: 612-617.

12 Niccoli G, Severino A, Pieroni M, et al. Parvovirus B19 at the culprit coronary stenosis predicts outcome after stenting. Eur J Clin Invest. 2014; 44: 209-218.

13 Corcioli F, Zakrzewska K, Rinieri A, et al. Tissue persistence of parvovirus B19 genotypes in asymptomatic persons. J Med Virol. 2008; 80: 2005-2011.

14 Pozzuto T, von Kietzell K, Bock T, et al. Transactivation of human parvovirus B19 gene expression in endothelial cells by adenoviral helper functions. Virology. 2011; 411: 50-64.

15 Bowles NE, Ni J, Kearney DL, et al. Detection of viruses in myocardial tissues by polymerase chain reaction: evidence of adenovirus as a common cause of myocarditis in children and adults. J Am Coll Cardiol. 2003; 42: 466-472. 